\title{
Layer-by-layer deposition of antimicrobial polymers on cellulosic fibers: a new strategy to develop bioactive textiles
}

\author{
Ana P. Gomes ${ }^{a *}$, João F. Mano ${ }^{b, c}$, João A. Queiroz ${ }^{d}$ and Isabel C. Gouveia ${ }^{a}$
}

\begin{abstract}
In recent years, there has been an increase of infectious diseases caused by different microorganisms and the development of antibiotic resistance. In this way, the search for new and efficient antibacterial materials is imperative. The main polysaccharides currently used in the biomedical and pharmaceutical domains are chitin and its derivative chitosan (CH) and alginates (ALG). In this study, a simple technique of Layer by Layer (LbL) of applying polycation CH and polyanion ALG was used to prepare CH/ALG multilayers on cotton samples via the electrostatic assembly with success. The CH/ALG cotton samples (functionalized) were investigated for their antibacterial properties towards Staphylococcus aureus and Klebsiella pneumonia using the international standard method JIS L 1902:2002. The antibacterial activity of the functionalized samples was tested in terms of bacteriostatic and bactericidal activity, and results showed that the samples exhibited a bacteriostatic effect on the two bacteria tested, as expected. In addition, samples with five layers (CH/ALG/CH/ALG/CH) were more effective in inhibiting bacterial growth. This new coating for cellulosic fibers is a new strategy and may open new avenues for the development of antimicrobial polymers with potential application in health-care field. Copyright $\odot 2013$ John Wiley \& Sons, Ltd.
\end{abstract}

Keywords: chitosan; alginate; cotton; LbL; JIS L 1902

\section{INTRODUCTION}

The number of different antimicrobial agents suitable for textile application on the market has increased drastically in recent years. Several different types of antimicrobial agents, such as oxidizing agents, coagulants, diphenyl ether (bis-phenyl) derivatives, heavy metals and metallic compounds and quaternary ammonium compounds are used in the textile industry to confer antimicrobial properties. ${ }^{[1]}$ The selection of the antimicrobial agent depends on the mechanism of antimicrobial activity (bacteria and fungi), toxicity, application method and cost. ${ }^{[1]}$ Nowadays, the textile manufactures prefer eco-friendly chemicals to impart antimicrobial finishing on textiles.

Polysaccharide biopolymers including ALG and $\mathrm{CH}$ have been the focus of an expanding number of studies reporting their potential use in biomedical research applications such as cell encapsulation, drug delivery and tissue engineering. Therefore, multilayered films containing both biopolymers could be useful in the coating of substrates for different biomedical applications, in particular in the development of new wound dressings. ${ }^{[2,3]}$

$\mathrm{CH}$, a natural biopolymer, has a combination of many unique properties such as biodegradability, non-toxicity, cationic nature, antitumor, immunostimulatory ${ }^{[4]}$ and antimicrobial activity. ${ }^{[5,6]}$ $\mathrm{CH}$ is also known in the wound management field for its hemostatic properties. ${ }^{[7]}$

ALG is a natural biopolymer, and it is non-toxic, biocompatible, biodegradable, less expensive and freely available. ${ }^{[8,9]}$ ALG is known to exhibit minimum cytotoxic effects and reduced hemolysis when in contact with blood. ${ }^{[8]}$

Electrostatic LbL assembly is a versatile method of fabricating multilayer films and coating from materials in solution, notably, oppositely charged polyelectrolytes in solution. Polyelectrolytes are polymers with ionizable groups along the chain, classified into anionic and cationic according to their functional group. An advantage of LbL is that the film is fabricated directly on the surface of interest. The method is based on the successive deposition of oppositely charged polymers onto solid surfaces. ${ }^{[10,11]}$ A deposition cycle creates a bilayer, and these cycles can be repeated as often as needed according to previous work. $^{[12]}$ The number of deposition cycles and the types of polyelectrolytes used in the construction allow for the control of thickness and roughness of the multilayered film. ${ }^{[13]}$ Figure 1 can illustrate this method.

Numerous studies involving different polymer substrates and several synthetic polyelectrolytes have been published. But,

\footnotetext{
* Correspondence to: Ana P. Gomes, R\&D Unit of Textile and Paper Materials, Faculty of Engineering, University of Beira Interior, 6201-001 Covilhã, Portugal. E-mail: anapaula@ubi.pt
}

\section{a A. P. Gomes, I. C. Gouveia}

R\&D Unit of Textile and Paper Materials, Faculty of Engineering, University of Beira Interior, 6201-001 Covilhã, Portugal

b J. F. Mano

3B's Research Group - Biomaterials, Biodegradables and Biomimetics, University of Minho, Headquarters of the European Institute of Excellence on Tissue Engineering and Regenerative Medicine, AvePark, 4806-909 Taipas, Guimarães, Portugal

C J. F. Mano

ICVS/3B's - PT Government Associate Laboratory, Braga/Guimarães, Portugal

d J. A. Queiroz

Health Sciences Research Centre, University of Beira Interior, 6201-001 Covilhã, Portugal 


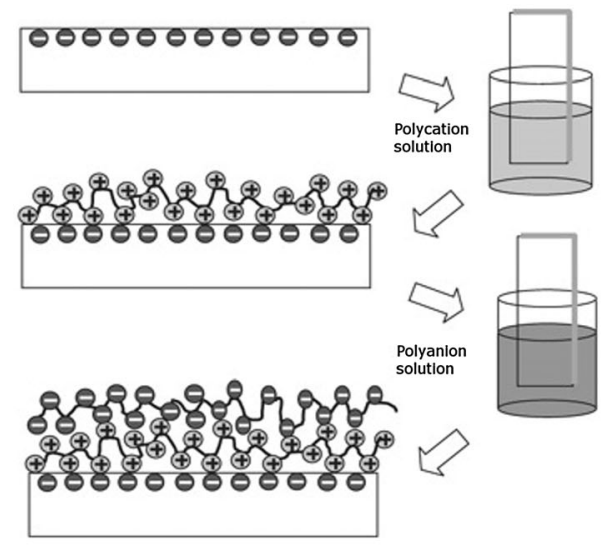

(a)

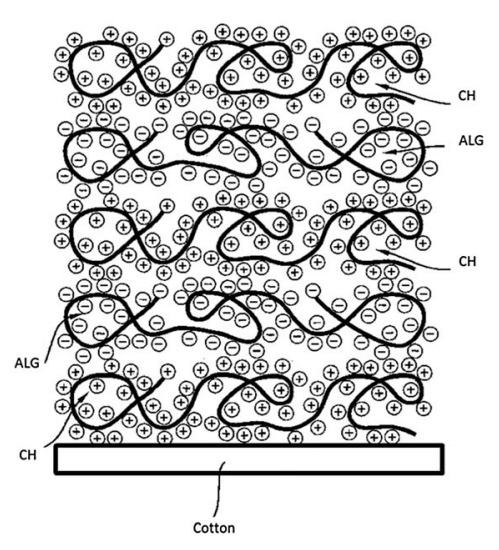

(b)

Figure 1. (a) The sequence of layer-by-layer electrostatic in negatively charged substrate, dipping into polycationic solution (CH), polycation layer deposited, dipping into polyanion solution (ALG), and the polyanion layer deposited. (b) Design of structure of the sample functionalized, adapted from Nabok, 2005. ${ }^{[14]}$

there are very few studies concerning the deposition of alternate polyelectrolyte on natural textile supports. Hyde et al. (2005) reported a pioneering application of self-assembly technique on cotton substrates by LbL deposition of poly (styrene sulfonate) (PSS) and poly (allylamine hydrochloride) on cotton fibers. ${ }^{[15]}$ Dubas et al. (2006) have immobilized antimicrobial silver nanoparticles on nylon and silk fibers by LbL deposition method. ${ }^{[16]}$

More recently, lamphaojeen et al. (2012), in this study, immobilized ZnO nanoparticles on cotton fabrics using PSS, through the LbL technique. As a result, they obtained a high UV protection factor and inhibition of the growth of Staphylococcus aureus. ${ }^{[17]}$

Based on literature review, the aim of this study was to design a new process for the bio-functionalization of cellulosic fibers with an antimicrobial effect with potential application as a new substrate for wound dressings. For this purpose, natural antimicrobial ingredients ( $\mathrm{CH}$ and $\mathrm{ALG}$ ) were deposited on cotton samples by LbL and investigated as a new potential antibacterial coating for cellulose-based textiles with a broad range of application in hospital, medical and hygienic products where antimicrobial activity is of the utmost importance

\section{EXPERIMENTAL}

\section{LbL coating of cotton}

To apply the LbL technique, anionic cotton was prepared by using 2,2,6,6,-tetramethylpiperidinyl-1-oxy free radical (TEMPO) and $\mathrm{NaBr}$, in order to give higher surface charge for polyelectrolyte deposition, as described elsewhere. ${ }^{[18]}$ Cotton samples were charged negatively by immersing cotton samples in TEMPO solution under moderate stirring, followed by a rinse with deionized water, according with literature. ${ }^{[19,20]}$ Chitosan of low molecular weight and $80 \%$ degree of deacetylation $(\mathrm{CH}, 1 \mathrm{mg} / \mathrm{ml})$, a natural antimicrobial polyelectrolyte, and Alginic acid sodium salt (ALG, $1 \mathrm{mg} / \mathrm{ml}$ ) solutions were prepared by dissolving $\mathrm{CH}$ and ALG in $0.1 \mathrm{M} \mathrm{CH} \mathrm{CH}_{3} \mathrm{COOH}$ and $0.5 \mathrm{M} \mathrm{NaCl}$ solutions, respectively. The $\mathrm{pH}$ values were adjusted to 5 using $0,1 \mathrm{M} \mathrm{HCl}$ and $1 \mathrm{~N}$ $\mathrm{NaOH}$ solutions.

The $\mathrm{pH}$ was selected to 5 , to be approximately intermediate between the $\mathrm{pK}_{\mathrm{a}}$ of $\mathrm{CH}(6.3)$ and $\mathrm{ALG}, \mathrm{pK}_{\mathrm{a}}$ of 3.38 and 3.65, as previously reported by other authors. ${ }^{[12,21]} \mathrm{ALG}$ and $\mathrm{CH}$ are two oppositely charged natural polyelectrolyte materials and very sensitive toward changes in external factor such as $\mathrm{pH}$. At $\mathrm{pH} 5$, the carboxylate group of ALG mainly exists in the form of $\mathrm{COO}^{-}$, and the amino group of $\mathrm{CH}$ mainly exists in the form of $\mathrm{NH}_{3}^{+}$. In this case, the presence of both $\mathrm{COO}^{-}$and $\mathrm{NH}_{3}^{+}$along polymer backbone could enhance the electrostatic interaction of the network structure ${ }^{[22]}$ (see Fig. 2).

Then, $\mathrm{CH}$ and ALG polyelectrolyte multilayer films were deposited over cotton by the LbL assembly, where $\mathrm{CH}$ was used as polycation and ALG as polyanion (see Fig. 2). For each layer deposition, the cotton substrate was immersed into the corresponding solution at room temperature for $5 \mathrm{~min}$, followed by rinsing with deionized water to remove the excess of polyelectrolyte. Since the cotton samples were charged negatively, the $\mathrm{CH}$ was deposited as the first layer. Cotton samples treated during $30 \mathrm{~min}$ in TEMPO (designated by $\mathrm{CT}$ ) and samples then functionalized by $\mathrm{LbL}$ were prepared with five layers (CH/ALG/ $\mathrm{CH} / \mathrm{ALG} / \mathrm{CH})$, six layers $(\mathrm{CH} / \mathrm{ALG} / \mathrm{CH} / \mathrm{ALG} / \mathrm{CH} / \mathrm{ALG})$, nine layers (CH/ALG/CH/ALG/CH/ALG/CH/ALG/CH) and ten layers (CH/ALG/ $\mathrm{CH} / \mathrm{ALG} / \mathrm{CH} / \mathrm{ALG} / \mathrm{CH} / \mathrm{ALG} / \mathrm{CH} / \mathrm{ALG})$, designated, respectively, by

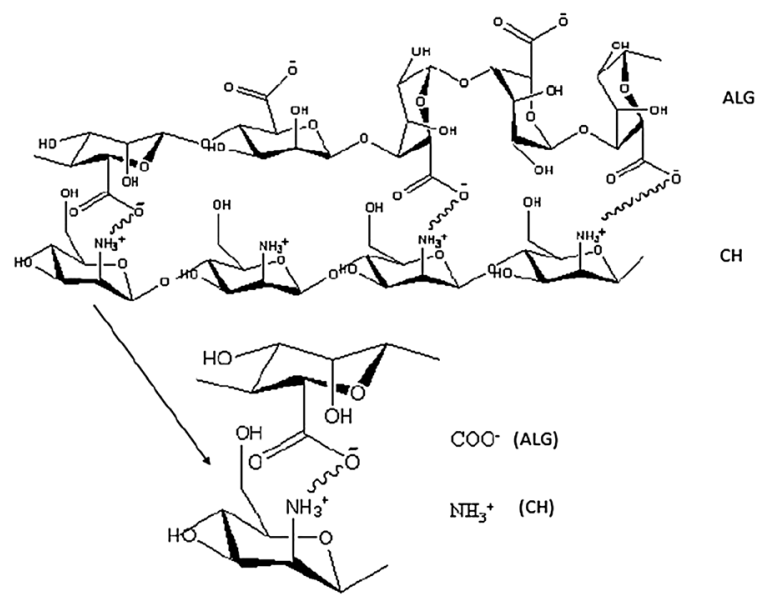

Figure 2. Schematic representation of the electrostatic interactions between the carboxylic groups of the ALG and the amine groups of the $\mathrm{CH}$, adapted from $\mathrm{Mi}$ et al., 2002. ${ }^{[23]}$ 
CT5, CT6, CT9 and CT10. After the last deposition, samples were dried in a desiccator at room temperature overnight. All chemicals were obtained from Sigma-Aldrich, are of analytical grade and were used as received.

\section{Assessment of antibacterial activity - JIS L 1902:2002 - halo method}

In order to evaluate the activity of antibacterial textiles, there are several standard methods available. The method used in this study and described in JIS L 1902 (Japanese Standard) appears to be the most commonly employed.

The culture medium Brain Heart Infusion used for the cultivation of the bacterial strains deployed in this work were prepared according with the instructions of the manufacturer. Culture media was dissolved directly after being weighed in deionized distilled water and then sterilized by autoclaving for $15 \mathrm{~min}$ at $121^{\circ} \mathrm{C}$. Agar was used to solidify the media before autoclaving. The strains of $S$. aureus and Klebsiella pneumoniae used were obtained from the American Type Culture Collection, ATCC 25923 and ATCC 13883, respectively. These strains were selected because they are indicated in several standards to evaluate antibacterial activity of textiles. ${ }^{[24]}$

The cell density of bacterial suspensions was determined by measuring the optical density (OD) of appropriately diluted samples using a spectrophotometer at a wavelength of $640 \mathrm{~nm}$ [OD 640 ]. $100 \mu \mathrm{l}$ aliquots of the appropriate dilutions were plated onto the surface of agar plates with a Mueller-Hinton medium, and after approximately $10 \mathrm{~min}$, the functionalized cotton samples were placed on the top of agar plates and incubated for $24 \mathrm{~h}$ at $37^{\circ} \mathrm{C} .{ }^{[25]}$

\section{Assessment of antibacterial activity - JIS L 1902:2002 - absorption method}

The JIS L 1902:2002 - absorption method is designed to quantitatively test the ability of textiles that have been treated with antibacterial agents to prevent bacterial growth and to kill bacteria, over an $18 \mathrm{~h}$ period of contact. This method is based on the quantitative determination of the potential effect and activity of functionalized samples, by the direct contact with a suspension of bacterial cells.

Textile samples with approximately $0.4 \mathrm{~g}$, six control samples (without $\mathrm{CH}$ and $\mathrm{ALG}$ ) and six samples functionalized with $\mathrm{CH}$ and $A L G$, previously sterilized in an autoclave at $121^{\circ} \mathrm{C}$ for $15 \mathrm{~min}$ were tested for each bacterial strain. In order to calculate growth reduction rate, three samples were used to measure the number of live bacteria after inoculation $\left(T_{0 h}\right)$ and the other three to measure the number of live bacteria after incubation $\left(\mathrm{T}_{18 \mathrm{~h}}\right)$.

Bacterial cell suspensions were collected from an overnight liquid culture in Nutrient Broth. After that, the bacterial concentration is adjusted to $1-2 \times 10^{8} \mathrm{cel} / \mathrm{ml}$ (equivalent to 0.5 McFarland), with the necessary dilutions to adjust the final bacterial concentration to $1 \pm 0.3 \times 10^{5} \mathrm{cel} / \mathrm{ml}$.

Each textile sample was placed in a $50 \mathrm{ml}$ Falcon tube, soaked with $200 \mu \mathrm{l}$ of the inoculum previously prepared, and $\mathrm{T}_{18 \mathrm{~h}}$ tubes were incubated for $18 \mathrm{~h}$ at $37^{\circ} \mathrm{C}$. For the release of bacterial cells from the textile samples, before and after the $18 \mathrm{~h}$ incubation period, $20 \mathrm{ml}$ of $0.85 \% \mathrm{NaCl}$ with surfactant Tween $80(0.2 \%)$ was added to the samples in $50 \mathrm{ml}$ Falcon tubes and vortexed. The resulting suspensions were used for the determination of viable counts using serial dilutions prepared in sterile $0.85 \%$ sodium chloride solution and plated. The plates were incubated at $37^{\circ} \mathrm{C}$ for $18 \mathrm{~h}$, and the number of colonies was counted visually using a microscope. This procedure was performed in triplicate. ${ }^{[25]}$ The growth reduction rate of the bacteria was calculated using the equation:

$$
\frac{T_{0 h}-T_{18 h}}{T_{0 h}} \times 100 \%=\text { reduction rate }(\%)
$$

where, $\mathrm{T}_{\mathrm{Oh}}$ is the $\mathrm{CFU} / \mathrm{ml}$ (CFU = colony forming units) of bacterial colonies at the initial stage $(0 \mathrm{~h})$, and $\mathrm{T}_{18 \mathrm{~h}}$ is the $\mathrm{CFU} / \mathrm{ml}$ of bacterial colonies after $18 \mathrm{~h}$ incubation. ${ }^{[24]}$

In order to carry out the judgement of test effectiveness, the growth value was calculated according to the following equation:

$$
\mathrm{F}=\mathrm{M}_{\mathrm{b}}-\mathrm{M}_{\mathrm{a}}
$$

When the growth value is more than 1.5 , the test is judged to be effective, and when the growth value is 1.5 or less, the test is judged to be not effective. When the test is not effective, a retest is necessary.

When the quantitative test has been effective, the bacteriostatic activity value should be calculated in accordance with the following equation:

$$
\mathrm{S}=\mathrm{M}_{\mathrm{b}}-\mathrm{M}_{\mathrm{c}}
$$

and the bactericidal activity according to:

$$
\mathrm{L}=\mathrm{M}_{\mathrm{a}}-\mathrm{M}_{\mathrm{c}}
$$

Where, $\mathrm{F}$ is the growth value, and $\mathrm{S}$ and $\mathrm{L}$ are the bacteriostatic and bactericidal activity values, respectively. $M_{a}$ is the average of common logarithm of number of living bacteria of three test pieces immediately after inoculation of inoculum on standard cloth. $M_{b}$ is the average of common logarithm of number of living bacteria of three test pieces after $18 \mathrm{~h}$ incubation on standard cloth. $M_{c}$ is the average of common logarithm of number of living bacteria of three test pieces after $18 \mathrm{~h}$ incubation on antibacterial treated sample. ${ }^{[25]}$ Traditionally, bacteriostatic means prevention of multiplication of bacteria without destroying them, whereas bactericidal effect implies forthright killing of the organisms ${ }^{[26]}$

\section{RESULTS AND DISCUSSION}

\section{Assessment of antibacterial activity - JIS L 1902:2002 - halo method}

The antibacterial efficacy of the $\mathrm{CH} / \mathrm{ALG}$ multilayers was evaluated by assessing the reduction in bacterial growth on the functionalized cotton substrates. Antibacterial activity analysis revealed that on the $\mathrm{CH} / \mathrm{ALG}$ functionalized cotton, the densities of attached bacteria decreased when compared with that of the control (cotton), as can be observed in Fig. 4 by the formation of a small halo on the functionalized samples. It appears that the effectiveness in preventing bacterial adhesion is high regardless of whether CH/ALG is deposited on cotton samples. This is in accordance with the expected. The use of $\mathrm{CH}$ as an anti-biofilm coating for medical applications has been suggested, as coating surfaces with $\mathrm{CH}$ is highly effective at restricting or preventing the formation S. aureus and K. pneumoniae biofilms. ${ }^{[27]}$ 
Cationic polyelectrolytes, as well as other molecules with a net positive charge, are capable of killing microorganisms. The mechanism of antibacterial action of cationic polyelectrolytes is not completely understood, but it has been suggested that these polymers can interact electrostatically with anionic groups at the bacterial cell walls causing an increase of membrane permeability and subsequent leakage of cellular proteins which ultimately leads to cell death. ${ }^{[28]}$ In the context of this research, the observed antibacterial action of the polyelectrolytes is an interesting finding because in principle the antimicrobial activity of the functionalized samples can be adjusted using favorable layers number of polyelectrolytes on top of cotton.

On the other hand, according with several authors, the $\mathrm{pH}$ value affects the antibacterial effect, where an increase in $\mathrm{pH}$ leads to a decrease of the antibacterial action. In the case of $\mathrm{CH}$, the high $\mathrm{pH}$ few amino groups in $\mathrm{CH}$ molecules will be free, but at $\mathrm{pH}$ below 6 , the amino groups become ionized. ${ }^{[4]}$ In this study, we use $\mathrm{pH} 5$; this implies a higher number of side amino groups available.

Likewise, the results of the JIS L 1902:2002 - qualitative method were used to assess the antibacterial activity of textile specimens.

In Fig. 3, a positive control (sample known to have antimicrobial activity) presents a halo around the sample. Halo size provides some indication of the potency of the antimicrobial activity of textile samples and also that the antimicrobial agent is released from the textile. In contrast, the results of the functionalized cotton (Fig. 4) showed an ambiguous inhibitory effect against $S$. aureus and $K$. pneumoniae, although in terms of the surrounding clearing zone, the different samples show the same inhibitory effect against all tested microorganisms.

Figure 4 (a) sample CT5, (b) samples CT6, CT9 and CT10, showed a small but clear inhibitory zone for $S$. aureus. Figure 4 (c) sample CT5, (d) samples CT6, CT9 and CT10, showed a smaller halo for the K. pneumonia. However, Fig. 4 (a) samples CO (cotton) and CT, and Fig. 4 (c) samples $C O$ and $C T$, showed a very thin inhibition line in the edges of the sample for both tested microorganisms. As a result, we conclude that for the $S$. aureus and K. pneumonia, the control samples (CO and CT) showed little microbial growth inhibition. In contrast, the inhibition was more significant in the presence of CH/ALG in samples CT5, CT6, CT9 and CT10.

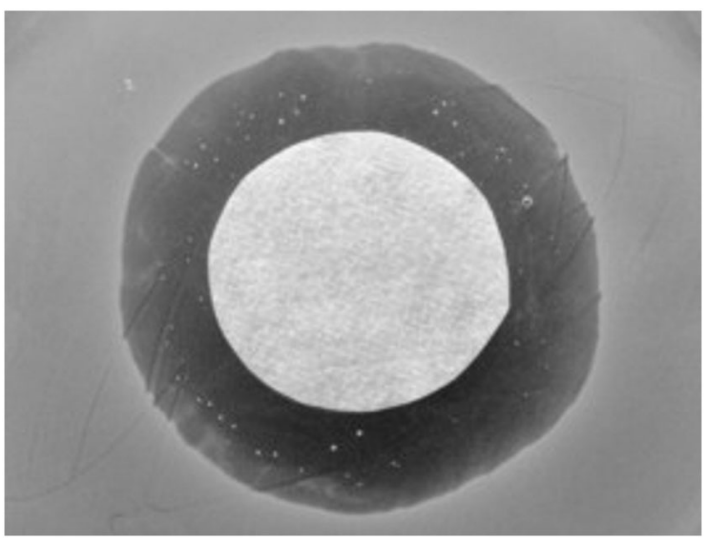

Figure 3. Image of a halo formation of a positive control (analysed using the standard method JIS L 1902:2002 - halo method, against Staphylococcus aureus).

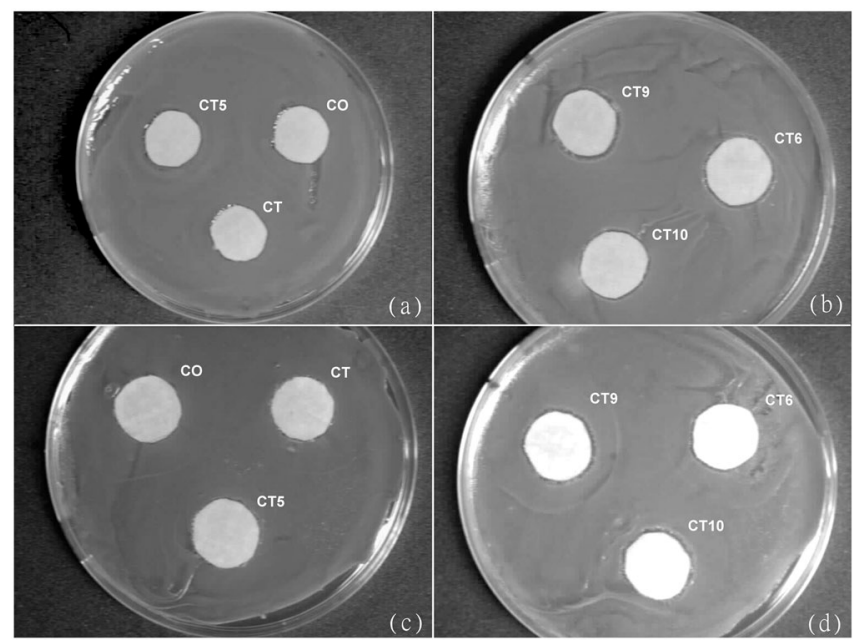

Figure 4. Images of samples tested according with the standard method JIS L 1902:2002 - halo method. a) and b), inhibition zone against Staphylococcus aureus for $\mathrm{CO}, \mathrm{CT}, \mathrm{CT} 5, \mathrm{CT} 6, \mathrm{CT} 9$ and $\mathrm{CT} 10$ samples. C) and d), inhibition zone against Klebsiella pneumonia for CO, CT, CT5, CT6, CT9 and CT10 samples.

From the little defined zone of inhibition obtained, it is apparent that the functionalized samples are bacteriostatic and not bactericidal. In addition, the results also showed that the antibacterial effect of $\mathrm{CH} / \mathrm{ALG}$ occurred without migration of the active agents. As CH/ALG are in a solid form, only microorganisms in direct contact with the active sites of CH/ALG are inhibited because $\mathrm{CH} / \mathrm{ALG}$ layers are incapable of diffusing through the adjacent agar medium, as discussed elsewhere. ${ }^{[29]}$ As a result, and as described previously, the possible mechanisms for antibacterial activity are: (1) the CH/ALG on the surface of the cell can form a polymer membrane, which prevents nutrients from entering the cell. (2) CH/ALG entered the cell through pervasion, since $\mathrm{CH}$ could absorb the electronegative substance in the cell and flocculate them; it disturbs the physiological activities of the bacteria. ${ }^{[30]}$

\section{Assessment of antibacterial activity - JIS L 1902:2002 - absorption method}

The antibacterial effect of functionalized samples was tested according to the Japanese Industrial Standard JIS L Standard 1902:2002. This method is based on the quantitative determination of the potential effect and activity of functionalized samples, by the direct contact with a suspension of bacterial cells. The results of the bioactivity investigations are presented in Table 1.

All samples (CT, CT5, CT6, CT9 and CT10) showed a bacteriostatic activity and no bactericidal activity found against $S$. aureus and $K$. pneumonia, being in accordance with the results for antibacterial activity by the halo method. CT5 is the sample that has the highest value of bacteriostatic activity (1.9 for S. aureus and 1.5 for K. pneumonia), followed by the sample CT9 (1.8 for $S$. aureus and 1.3 for $K$. pneumonia). These samples have in common the last layer is composed for $\mathrm{CH}$, suggesting more free amino groups from CT5 and CT9 and lower free amino groups from the CT6 and CT10, which are bonded with carboxylic groups of the ALG thus, reducing the activity. The experimental results provide tangible evidence in support of the hypothesis that the amino group on $\mathrm{CH}$ is a source of bacteriostatic activity. 


\begin{tabular}{|c|c|c|c|c|}
\hline \multirow[t]{2}{*}{ Sample } & \multicolumn{2}{|c|}{ S. aureus } & \multicolumn{2}{|c|}{ K. pneumoniae } \\
\hline & $M_{b}-M_{c}$ & $M_{a}-M_{c}$ & $M_{b}-M_{c}$ & $M_{a}-M_{c}$ \\
\hline $\mathrm{CO}$ & 0 & -1.5 & 0 & -1.8 \\
\hline $\mathrm{CT}$ & 0.3 & -1.1 & 0.2 & -1.0 \\
\hline CT5 & 1.9 & -0.5 & 1.5 & -0.4 \\
\hline СТ6 & 1.3 & -1.0 & 1.1 & -0.9 \\
\hline CT9 & 1.8 & -0.6 & 1.3 & -0.6 \\
\hline CT10 & 1.4 & -0.7 & 1.1 & -0.8 \\
\hline \multicolumn{5}{|c|}{$\begin{array}{l}\text { A-number of inoculated bacteria. B-number of bacteria on } \\
\text { the standard sample contacted for } 18 \mathrm{~h} \text {. C-number of } \\
\text { bacteria on the functionalized sample after incubation for } \\
18 \mathrm{~h} . M_{a}=\log A, M_{b}=\log B, M_{c}=\log C \text {. Bacteriostatic } \\
\text { activity level, } M_{b}-M_{c} \text { bactericidal activity level, } M_{a}-M_{c} \text {. }\end{array}$} \\
\hline
\end{tabular}

In literature, normally the $\mathrm{CH}$ exhibits a stronger bioactivity effect upon Gram-positive than Gram-negative bacteria. This observation may be explained by the higher deacetylation degree of $\mathrm{CH}$ used in this work (80\%), which implies a higher number of side amine groups available for reaction. ${ }^{[4,27]}$ On the other hand, the bioactivity effect also depends on the molecular weight; the inhibitory effect decrease slightly as the molecular weight increase. In this study, it was used $\mathrm{CH}$ of low molecular weight $(420 \mathrm{kDa}) . \mathrm{CH}$ is a cation that attracts the negative charges of the cell walls of bacteria, as claimed by several authors, being the cause for $\mathrm{CH}$ antibacterial action. $^{[31-34]}$ The surface of $S$. aureus includes the negatively charged teichoic acid within a thick peptidoglycan layer that lacks an outer membrane. ${ }^{[35]}$ This should render the bacterial cell more attractive to and easier to be damaged through electrostatic-mediated contact-inhibition mechanisms when exposed to the positively charged $\mathrm{CH}$ layer (CT5 and CT9) than the negatively charged ALG layer (CT6 and CT10).

The lower bacteriostatic activity of the samples against $K$. pneumonia than that against $S$. aureus may be explained as a result of the different bacterial membrane structures. In contrast to that of S. aureus, K. pneumonia has a double protective layer, the outer lipopolysaccharide layer embedded with a number of small channels of porins and the inner peptidoglycan layer. The fact that it does not contain the negatively charged (teichoic acid) entities that can interact with positively charged molecules would potentially make it less sensitive to electrostatic binding with positively charged molecules like $\mathrm{CH}^{[35]}$

The work on the effect of $\mathrm{CH}$ in strains of $K$. pneumonia and S. aureus found that $\mathrm{CH}$ promotes aggregation of bacterial cells and disorganization of bacterial cell wall and cytoplasmic membrane, which leads to the release of bacterial contents into the environment. These structural changes result in bacterial death. ${ }^{[36]}$ These results suggest that the apparent difference action upon Gram-positive and Gram-negative microorganisms probably results from the intrinsic difference in their cell wall structure.

All functionalized samples (CT5, CT6, CT9 and CT10) showed antibacterial activity against $S$. aureus and $K$. pneumonia in solution. Figure. 5 shows the growth inhibition (cell reduction) of the S. aureus and K. pneumonia by the antibacterial activity of the functionalized samples with CH/ALG.

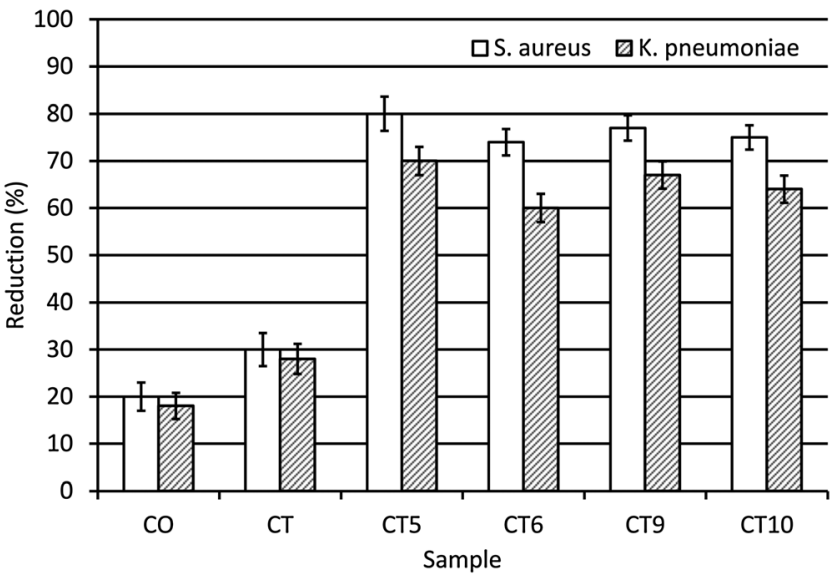

Figure 5. Reduction rate (\%) of Staphylococcus aureus and Klebsiella pneumoniae in functionalized samples.

Analyzing the results, (Fig. 5) there is a reduction of $65-80 \%$ in bacterial growth on CT5 and CT9 samples, respectively, and a reduction of $60-75 \%$ in bacterial growth is achieved by CT6 and CT10 samples. An interesting observation is that all functionalized samples exhibit a high reduction of bacterial growth in solution although without a clear zone of inhibition assessed by the halo method. This may be because the concentration of $\mathrm{CH}$ and ALG on cotton samples is not sufficient enough for bactericidal activity as described elsewhere. ${ }^{[37]}$ Singh and co-workers found that antimicrobial efficacy of a compound will vary when it is present in solution and when it is held intimately by a textile substrate. $^{[37]}$

All of these results suggest that the functionalized samples with five numbers of layers $(\mathrm{CH} / \mathrm{ALG} / \mathrm{CH} / \mathrm{ALG} / \mathrm{CH})$ are more active against $S$. aureus and $K$. pneumonia microorganisms.

Structurally, the cationic nature of $\mathrm{CH}$ is expected to interact strongly by ionic bonds with the anionic ALG, and the combination of ALG with $\mathrm{CH}$ has become quite commonplace for the development of potential wound healing materials as they showed no toxic effects to mammalian cells. ${ }^{[38]}$ A recent study has shown that $\mathrm{ALG} / \mathrm{CH}$-based wound dressing films accelerated burn healing by modulating the epithelization, blood vessels formation and collagenization process. ${ }^{[39]}$

\section{CONCLUSION}

The results obtained confirm the possibility of using the LbL method for modification of the surfaces of cotton fabric in order to impart antibacterial properties to them. The most important potential application of these materials could be their use as external wound dressings. Their advantage toward the existing materials is that they are fully biocompatible and inexpensive.

Many applications are proposed based on this $\mathrm{CH} / \mathrm{ALG}$, which is the most investigated polyelectrolyte complex, especially for biomedical applications. Note that this technique (LbL) in textile is entirely new and is a simple and effective method with strong possibility of industrial application.

This new coating for cellulosic fibers is a new strategy and may open new avenues for the development of antimicrobial polymers with potential application in health-care field. 


\section{Acknowledgements}

The authors would like to thank Fundação para a Ciência e Tecnologia (FCT) for the funding granted concerning the project - PTDC/EBB-BIO/ 113671/2009 (FCOMP-01-0124-FEDER-014752) Skin2Tex. Also, we would like to thank Fundo Europeu de Desenvolvimento Regional (FEDER) through COMPETE - Programa Operacional Factores de Competitividade (POFC) for the co-funding.

\section{REFERENCES}

[1] L. Ammayappan, J. J. Moses, Study of antimicrobial activity of aloevera, chitosan, and curcumin on cotton, wool, and rabbit hair. Fibers Polym. 2009, 10(2), 161-166.

[2] G. Lawrie et al., Interactions between alginate and chitosan biopolymers characterized using FTIR and XPS. Biomacromolecules 2007, 8(8), 2533-2541.

[3] N. M. Alves, C. Picart, J. F. Mano, Self Assembling and Crosslinking of Polyelectrolyte Multilayer Films of Chitosan and Alginate Studied by QCM and IR Spectroscopy. Macromol. Biosci. 2009. 9(8) 776-785.

[4] J. C. Fernandes et al., In Vitro Screening for Antimicrobial Activity of Chitosans and Chitooligosaccharides, Aiming at Potential Uses in Functional Textiles. J. Microbiol. Biotechnol. 2010, 20(2), 311-318.

[5] M. George, T. E. Abraham, Polyionic hydrocolloids for the intestinal delivery of protein drugs: Alginate and chitosan - a review. J. Control. Release 2006, 114(1), 1-14.

[6] S. Honary, M. Maleki, M. Karami, The effect of chitosan molecular weight on the properties of alginate/chitosan microparticles containing prednisolone. Trop. J. Pharm. Res. 2009, 8(1), 53-61.

[7] O. L. Shanmugasundaram, R. V. M. Gowda, Development and Characterization of Bamboo Gauze Fabric Coated with Polymer and Drug for Wound Healing. Fibers Polym. 2011, 12(1), 15-20.

[8] A. Shilpa, S. S. Agrawal, A. R. Ray, Controlled delivery of drugs from alginate matrix. J. Macromol. Sci.-Polym. Rev. 2003, C43(2), 187-221.

[9] C. K. Kuo, P. X. Ma, lonically crosslinked alginate hydrogels as scaffolds for tissue engineering: Part 1. Structure, gelation rate and mechanical properties. Biomaterials 2001, 22(6), 511-521.

[10] G. Decher, J. D. Hong, J. Schmitt, Buildup of Ultrathin Multilayer Films by a Self-Assembly Process .3. Consecutively Alternating Adsorption of Anionic and Cationic Polyelectrolytes on Charged Surfaces. Thin Solid Films 1992, 210(1-2), 831-835.

[11] Y. Lvov, G. Decher, H. Mohwald, Assembly, Structural Characterization, and Thermal-Behavior of Layer-by-Layer Deposited Ultrathin Films of Poly(Vinyl Sulfate) and Poly(Allylamine). Langmuir 1993. 9(2), 481-486.

[12] A. P. Gomes et al., Layer-by-Layer Deposition of Antibacterial Polyelectrolytes on Cotton Fibres. J. Polym. Environ. 2012, 20(4), 1084-1094.

[13] C. Picart et al., Determination of structural parameters characterizing thin films by optical methods: A comparison between scanning angle reflectometry and optical waveguide lightmode spectroscopy. J. Chem. Phys. 2001, 115(2), 1086-1094.

[14] A. Nabok, Organic and inorganic nanostructures. Microelectromechanical systems series. 2005, Boston: Artech House. xi, 268.

[15] K. Hyde, M. Rusa, J. Hinestroza, Layer-by-layer deposition of polyelectrolyte nanlayers on natural fibres: cotton. Nanotechnology, 2005, 16(7), S422-S428.

[16] S. T. Dubas, P. Kumlangdudsana, P. Potiyaraj, Layer-by-layer deposition of antimicrobial silver nanoparticles on textile fibers. Colloids Surf., A 2006, 289(1-3), 105-109.

[17] Y. lamphaojeen, P. Siriphannon, Immobilization of zinc oxide nanoparticles on cotton fabrics using poly 4-styrenesulfonic acid polyelectrolyte. Int. J. Mater. Res. 2012, 103(5), 643-647.
[18] R. A. Jewell, B., WA (US); Joseph L. Komen, Bothell, WA (US); Bing Su, Federal Way, WA (US); s. Ananda Weerawarna, Seattle, WA (US); Yong Li, Tacoma, WA (US). Method of making carboxylated cellulose fibers and products of the method. Patent No US 6524 348 B1

[19] T. Saito et al., TEMPO-mediated oxidation of native cellulose: Microscopic analysis of fibrous fractions in the oxidized products. Carbohydr. Polym. 2006, 65(4), 435-440.

[20] Z. Dang, J. G. Zhang, A. J. Ragauskas, Characterizing TEMPOmediated oxidation of ECF bleached softwood kraft pulps. Carbohydr. Polym. 2007, 70(3), 310-317.

[21] G. Maurstad et al., Polyelectrolyte layer interpenetration and swelling of alginate-chitosan multilayers studied by dual wavelength reflection interference contrast microscopy. Carbohydr. Polym. 2008, $71(4), 672-681$.

[22] Y. Ding, et al., Assembled alginate/chitosan micro-shells for removal of organic pollutants. Polymer 2009, 50(13), 2841-2846.

[23] Mi, F. L., H. W. Sung, S. S. Shyu, Drug release from chitosan-alginate complex beads reinforced by a naturally occurring cross-linking agent. Carbohydr. Polym., 2002. 48(1): p. 61-72.

[24] S. J. Park, Y. M. Park, Eco-dyeing and Antimicrobial Properties of Chlorophyllin Copper Complex Extracted from Sasa veitchii. Fibers Polym. 2010, 11(3), 357-362.

[25] JIS L 1902, Testing for antibacterial activity and efficacy on textile products, 2002: Japanese Industrial Standard.

[26] G. A. Pankey, L. D. Sabath, Clinical relevance of bacteriostatic versus bactericidal mechanisms of action in the treatment of gram-positive bacterial infections. Clin. Infect. Dis. 2004, 38(6), 864-870.

[27] H. K. No et al., Antibacterial activity of chitosans and chitosan oligomers with different molecular weights. Int. J. Food Microbiol. 2002, $74(1-2), 65-72$

[28] N. C. T. Martins et al., Electrostatic assembly of Ag nanoparticles onto nanofibrillated cellulose for antibacterial paper products. Cellul. 2012, 19(4), 1425-1436.

[29] S. Tripathi, G. K. Mehrotra, P. K. Dutta, Physicochemical and bioactivity of cross-linked chitosan-PVA film for food packaging applications. Int. J. Biol. Macromol. 2009, 45(4), 372-376.

[30] L. Y. Zheng, J. A. F. Zhu, Study on antimicrobial activity of chitosan with different molecular weights. Carbohydr. Polym. 2003, 54(4), 527-530.

[31] L. F. Qi, et al., Preparation and antibacterial activity of chitosan nanoparticles. Carbohydr. Res. 2004, 339(16), 2693-2700.

[32] X. H. Wang et al., Chitosan-metal complexes as antimicrobial agent: Synthesis, characterization and structure-activity study. Polym. Bull. 2005, 55(1-2), 105-113.

[33] S. H. Hsieh, J. H. Ciou, J. J. Wang, Preparation and multifunctional application of meso-chitosan for the woolen process. J. Appl. Polym. Sci. 2007, 103(6), 4080-4086.

[34] Y. C. Chung, C. Y. Chen, Antibacterial characteristics and activity of acid-soluble chitosan. Bioresour. Technol. 2008, 99(8), 2806-2814.

[35] W. Graisuwan et al., Multilayer film assembled from charged derivatives of chitosan: Physical characteristics and biological responses. J. Colloid Interface Sci. 2012, 376, 177-188.

[36] L. V. Didenko, N. D. Konstantinova, T. A. Silkina, Ultrastructural study of chitosan effects on Klebsiella and Staphylococci. Bull. Exp. Biol. Med. 2005, 140(3), 356-360.

[37] R. Singh et al., Antimicrobial activity of some natural dyes. Dyes Pigm. 2005, 66(2), 99-102.

[38] Liakos, l., et al., Controlled antiseptic release by alginate polymer films and beads. Carbohydr. Polym. 2013, 92(1), 176-183.

[39] M. D. M. Dantas et al., Improvement of dermal burn healing by combining sodium alginate/chitosan-based films and low level laser therapy. J. Photochem. Photobiol. B 2011, 105(1), 51-59. 